\title{
Unidade de ensino potencialmente significativa para o estudo da água e polvição na perspectiva da educação ambiental crítica
}

Cristiane Jussara da Silva*, Helotonio Carvalho**, Kátia Aparecida da Silva Aquino***

\section{Resumo}

A poluição litorânea está na lista dos graves problemas ambientais que prejudicam a sociedade e a manutenção dos ecossistemas. Considerando esse cenário e a complexidade que envolve os problemas ambientais é importante que as escolas, não mais de forma ingênua, realizem ações que conversem com os diversos saberes curriculares com uso de ferramentas e estratégias de ensino que sejam potencialmente significativas. Nesse contexto, foi desenvolvida uma Unidade de Ensino Potencialmente Significativa (UEPS) acerca da temática "Água e Poluição na Educação Básica". A UEPS foi idealizada utilizando uma sequência de ações de ensino de modo interdisciplinar utilizando uma variedade de estratégias e ferramentas e com a avaliação pautada na produção de mapas conceituais, tendo sido aplicada a estudantes do ensino médio de uma escola da rede estadual de Pernambuco. Durante as estratégias didáticas utilizadas foram encontradas evidências de que novos conceitos se ancoraram aos conhecimentos prévios dos estudantes, sendo indício de uma aprendizagem significativa em curso. A aplicação das diversas etapas da UEPS contribuiu para a formação de estudantes que passaram a ser protagonistas juvenis, com a possibilidade de entenderem a complexidade da problemática da poluição litorânea, além de desenvolverem responsabilidade ambiental, social e política.

Palavras-chave: Aprendizagem Significativa. Ensino de Ciências. Mapa Conceitual. UEPS.

* Mestre em Ensino de Ciências Ambientais (ProfCiamb-UFPE). Docente da Secretaria de Educação do Estado de Pernambuco. Brasil. E-mail: cris.jussara@hotmail.com

* Membro permanente do Programa de Pós-graduação em Rede para o Ensino das Ciências Ambientais (ProfCiamb-UFPE). Brasil. E-mail: helotonio.carvalho@gmail.com

** Membro permanente do Programa de Pós-graduação em Rede para o Ensino das Ciências Ambientais (ProfCiamb-UFPE). Docente do Colégio de Aplicação da UFPE. Brasil. Autor de correspondência. E-mail: aquino@ ufpe.br

Recebido em: 15/09/2020; Aceito em: 19/08/2021

https://doi.org/10.5335/rbecm.v4i2.11047

http://creativecommons.org/licenses/by-nc-nd/4.0

ISSN: 2595-7376 


\section{Introdução}

Trazer para o estudante a complexidade de temas sobre degradação e poluição ambiental, utilizando práticas tradicionais e ignorando que o ensino na atualidade deve desenvolver competências cognitivas, pessoais e sociais é ter um parâmetro, no mínimo ultrapassado, do ensino e da aprendizagem. Na década de 1960, David Ausubel propôs a chamada Teoria de Aprendizagem Significativa (TAS) como alternativa para o que ele denominava concepção behaviorista de aprendizagem. Segundo Moreira (2017), para Ausubel a concepção behaviorista (comportamentalista) da aprendizagem via o estudante como um ser meramente passivo, ao qual não se dava elementos estimuladores para desenvolver sua criticidade. A fim de superar esses supostos problemas, Ausubel (1963) propôs uma teoria abrangente de como os seres humanos aprendem e retêm conhecimentos em sala de aula e ambientes de aprendizagem análogos, cujo escopo estaria limitado ao aprendizado por recepção e retenção de material significativo. Para Ausubel (1963), aprendizagem por recepção referia-se às situações nas quais o conteúdo da tarefa de aprendizagem (o que é aprendido) é apresentado ao invés de descoberto independentemente pelo aluno. Basicamente, a TAS considera a aprendizagem como o resultado da constante reestruturação da chamada estrutura cognitiva da mente humana. Obras como as de Ausubel, Novak e Hanesian (1980), Moreira (2010, 2011) e Novak e Cañas (2010) vem tentando refinar a TAS e apresentar ideias para seu uso ostensivo em sala de aula.

Dentro dessa perspectiva, procurou-se, nesse trabalho, fomentar uma Educação Ambiental Crítica (EAC) fundamentada em uma visão holística da realidade e nos métodos da interdisciplinaridade, que traga discussões sobre a ineficácia do conhecimento fragmentado e da não contextualização das problemáticas ambientais do estudante (CARVALHO; LAYRARGUES, 2012). As conferências ambientais mundiais da década de 1970 já evidenciavam que ações ordenadas, com o propósito de preservar o meio ambiente, eram práticas indissociáveis do ensino formal. A institucionalização, no Brasil, dos documentos educacionais (Parâmetros Curriculares Nacionais e Base Nacional Comum Curricular), com o tema Meio Ambiente, passou a ser garantida no currículo escolar, como eixo transversal, em razão de sua abrangência, complexidade e importância (BRASIL, 2006). Nessa direção, autores como Loureiro e Layrargues (2006) sugerem que a prática da educação ambiental, 
para ser efetiva, deve estar fundamentada numa perspectiva que estimule o pensar e o agir crítico do estudante.

Loureiro (2007) expõe que as escolas utilizam práticas de Educação Ambiental apenas com ações de sensibilização e/ou conscientização do convívio com a natureza, salvo raras exceções. Essa é a causa, segundo o autor, do frágil diálogo entre a escola e a comunidade onde ela está inserida. $\mathrm{O}$ que também precisa ser levado em consideração, de acordo com Carvalho e Toniol (2010), são os novos fenômenos que reconfiguram as práticas tradicionais e que precisam ser incorporados aos temas ambientais. A escola deve ser, portanto, um espaço aberto, que permita que as questões socioambientais sejam discutidas mesmo nos ambientes mais vulneráveis, fazendo, com isso, o encurtamento da distância entre as políticas públicas e o que efetivamente acontece dentro das escolas (MACHADO; MORAIS, 2019).

Essa responsabilidade da escola fica muito evidente no mais recente documento oficial nacional, que direciona a educação no país, a Base Nacional Comum Curricular (BNCC) que, em uma de suas competências gerais, preconiza que o estudante deve ser preparado para

\begin{abstract}
Argumentar com base em fatos, dados e informações confiáveis, para formular, negociar e defender ideias, pontos de vista e decisões comuns que respeitem e promovam os direitos humanos, a consciência socioambiental e o consumo responsável em âmbito local, regional e global, com posicionamento ético em relação ao cuidado de si mesmo, dos outros e do planeta (MARINI, 2018, p. 10).
\end{abstract}

Pelo exposto, ao se trabalhar a complexa problemática ambiental, como a poluição do Complexo Estuarino do Canal de Santa Cruz, é possível evidenciar o processo de degradação ou poluição, principalmente se o ambiente tratado for local, o que permite que seja vivenciado pelos estudantes. Neste cenário, a compreensão da sua dimensão não deve ser abordada de forma fragmentada e restrita apenas ao componente curricular de Biologia, por exemplo, visto que nenhum componente curricular apresenta primazia intelectual sobre qualquer outra na busca da sustentabilidade (COIMBRA, 2000). O que não descarta a importância do ensino de Biologia como um momento oportuno para o desenvolvimento de competências relacionadas à criticidade e observância de eventos e fenômenos que ocorrem ao redor dos estudantes. Além disso, o estudo de um canal estuarino, ao deixar emergir sua importância socioambiental e econômica, propicia discussões que podem ser um rico campo de desenvolvimento crítico no tocante à prática do professor, linha 
pedagógica da escola e formação de uma conduta ecológica e cidadã do estudante. Contudo, são necessárias práticas pedagógicas que promovam um ensino que também seja significativo e crítico para os estudantes.

\section{Teoria da aprendizagem significativa crítica e as Unidades de Ensino Potencialmente Significativas (UEPS)}

O ensino na contemporaneidade deve buscar uma aprendizagem que seja significativa e que prepare o estudante para participar ativamente do seu processo de ensino-aprendizagem. Entretanto, as práticas pedagógicas atualmente utilizadas, de acordo com Moreira e Massine (2015), salvo algumas exceções, continuam baseadas em "fazer exercícios repetitivos, estudar na véspera das provas, decorar respostas corretas". Ausubel, na década de 1960, vem como pioneiro na visão de aprendizagem cognitivista, na qual a sua principal preocupação era em como facilitar ao aprendiz a aprendizagem com significado, de um corpo organizado de conhecimentos em situação formal de ensino (MOREIRA, 2017).

Ausubel, Novak e Hanesiam (1980) se referiram, ao conhecimento prévio ou subsunçor do estudante como um "ancoradouro" para os novos conceitos que passarão a ter significado na estrutura cognitiva do aprendiz. Para os autores, suas pesquisas na área de psicologia educacional poderiam ser resumidas a um único princípio: "O fator isolado mais importante que influencia a aprendizagem é aquilo que o aprendiz já conhece. Descubra o que ele sabe e baseie nisso os seus ensinamentos" (AUSUBEL, 1980, p. 1).

Caso o aprendiz não disponha desses subsunçores, ele indicou os organizadores prévios, que têm a função de servir de ponte entre o que o estudante não sabe e o que ele precisa saber, sendo eles mais abrangentes e inclusivos do que os materiais potencialmente significativos. Dentro dessa linha, Moreira (2010) aponta que se deve acolher as ideias prévias dos estudantes e construir diversificadas situações de aprendizagem dando à TAS um viés crítico, surgindo a chamada Teoria da Aprendizagem Significativa Crítica, que se configura a partir de princípios facilitadores, que ajudam o estudante a enxergar o conteúdo potencialmente significativo com a ideia de aplicá-lo nas situações cotidianas, o que faz o conhecimento, em termos cognitivos, reorganizar-se e adquirir novos significados em relação ao que, até então, poderia estar sendo visto de forma isolada (MOREIRA, 2012). 
Neste contexto, a Unidade de Ensino Potencialmente Significativa (UEPS), idealizada por Marco Antônio Moreira, é um tipo de sequência didática que satisfaz a necessidade educacional de buscar a melhor maneira de relacionar explicitamente os aspectos mais importantes de uma temática a ser abordada, aos aspectos especificamente relevantes de estrutura cognitiva do aprendiz e assim promover uma aprendizagem significativa (MOREIRA, 2011). O autor ressalta que a busca por evidências da aprendizagem significativa deve ser sempre o objetivo-fim para o professor que pretende utilizar uma UEPS como ferramenta da aprendizagem (MOREIRA, 2011).

Moreira explica que essa ferramenta é constituída por sequências de ensino, fundamentadas teoricamente que não devem utilizar uma abordagem mecânica e, sim, significativa nas pesquisas de ensino que forem utilizadas (MOREIRA, 2011). As etapas de uma UEPS são: 1. Conhecimento prévio: $O$ aluno externaliza seu conhecimento prévio, aceito ou não-aceito no contexto da matéria de ensino; 2. Situações-problemas introdutórias: Preparam o terreno para a introdução do conhecimento (declarativo ou procedimental) que se pretende ensinar e que serão, cuidadosamente, mediadas no sentido de despertar a intencionalidade do discente em aprender significativamente. 3. Diferenciação progressiva: Deverá partir dos aspectos mais gerais, do que é mais importante na unidade de ensino, para o mais específico; 4 Situações-problemas complexas: Deverão ser propostas em níveis crescentes de complexidade com uso de materiais potencialmente significativos. $\mathbf{5}$. Reconciliação integradora: Nessa fase, existe a possibilidade de ir e voltar com o conteúdo temático onde essas situações podem ser resolvidas em atividades colaborativas, sempre com a mediação do docente; 6. Avaliação: Deverá ser formadora e recursiva na busca de evidência de uma aprendizagem significativa, que se sabe ser progressiva.

O professor mediador do processo de construção de uma UEPS deve estar atento ao que afirma seu idealizador ao falar da importância dos materiais e as estratégias de ensino, que devem ser diversificados para propiciar e estimular o diálogo, o questionamento e a crítica (MOREIRA, 2011). Para isso, privilegiam-se as atividades colaborativas e momentos de atividades individuais. Alguns exemplos das UEPS desenvolvidas para Mestrados Profissionais como Produto Educacional pelas Universidades Brasileiras são apresentados no Quadro 1. O repositório escolhido para essa breve pesquisa foi o Banco de Teses e Dissertações da Coordenação 
de Aperfeiçoamento de Pessoal de Nível Superior (CAPES). Nesse repositório, encontram-se teses e dissertações apresentadas nos programas de pós-graduação de todo o país. Foram encontrados um total de 161 UEPS nesse repositório. O Quadro 1 lista apenas uma amostra de UEPS produzidas recentemente, mas já evidencia a realidade de pequena produção deste produto educacional na área de Ciências Naturais. Este fato é também constatado no repositório do Mestrado Profissional em Rede Nacional para o Ensino de Ciências Ambientais, polo Universidade Federal de Pernambuco (PROFCIAMB-UFPE), de onde os professores pesquisadores deste trabalho fazem parte, sendo a UEPS apresentada, a primeira a fazer parte do repositório desse programa.

Para a etapa de avaliação, os mapas conceituais são ferramentas de importante relevância por terem sido criadas com base na teoria da Aprendizagem Significativa de David Ausubel (1963). De acordo com Novak e Cañas (2010), para se elaborar um mapa conceitual, é importante que a área de conhecimento seja bastante familiar para quem vai elaborá-lo, uma vez que a estrutura hierárquica do mapa conceitual depende do contexto no qual será usado. Partindo de uma boa pergunta, o Mapa Conceitual passará a representar relações significativas entre conceitos na forma de proposições. Elas são constituídas de dois ou mais termos conceituais unidos por palavras para formar uma unidade semântica (NOVAK; CAÑAS, 2010).

Os mapas conceituais podem ser construídos tanto de forma manual como pelo uso do programa CmapTools que é um aplicativo que, segundo Novak e Cañas (2010), alia a qualidade do mapa conceitual ao uso de Tecnologias Digitais de Informações e Comunicações (TDICs). O software facilita o uso para usuários de todas as idades elaborarem e modificarem seus mapas. É essa versatilidade que faz essa ferramenta ser promissora no acompanhamento e desenvolvimento de uma UEPS, justificando, assim, sua escolha para validar a UEPS proposta neste estudo. 
Quadro 1: Algumas dissertações que construíram UEPS como produto educacional

\begin{tabular}{|c|c|c|}
\hline Tema da UEPS & Programa & Referência \\
\hline $\begin{array}{l}\text { Ensino de conceitos de termodinâmica: es- } \\
\text { tação meteorológica como possibilidade de } \\
\text { aprendizagem em Física. }\end{array}$ & $\begin{array}{l}\text { Mestrado Profissional em Ensino de Ciências } \\
\text { Naturais da Universidade Federal de Mato } \\
\text { Grosso }\end{array}$ & CONTIN, 2018 \\
\hline $\begin{array}{l}\text { Proposta de uma UEPS para ensinar o efei- } \\
\text { to fotoelétrico no ensino médio. }\end{array}$ & $\begin{array}{l}\text { Mestrado Profissional em Ensino de Física da } \\
\text { Universidade de Brasília }\end{array}$ & LIMA, 2018 \\
\hline $\begin{array}{l}\text { Inserção dos conceitos da radiação do cor- } \\
\text { po negro no ensino médio através de uma } \\
\text { sequência didática baseada em uma UEPS }\end{array}$ & $\begin{array}{l}\text { Mestrado Profissional em Ensino de Física do } \\
\text { Instituto Federal de Educação, Ciência e Tec- } \\
\text { nologia do Amazonas }\end{array}$ & FILHO, 2018 \\
\hline $\begin{array}{l}\text { Proposta de UEPS abordando conceitos en- } \\
\text { volvidos no processo de ensino e aprendiza- } \\
\text { gem da eletroquímica. }\end{array}$ & $\begin{array}{l}\text { Mestrado Profissional em Ensino de Ciências } \\
\text { Naturais e Matemática da Universidade Fede- } \\
\text { ral do Rio Grande do Norte }\end{array}$ & $\begin{array}{l}\text { MEDEIROS, } \\
2018\end{array}$ \\
\hline $\begin{array}{l}\text { Unidade de Ensino Potencialmente Signifi- } \\
\text { cativa para estudo do sistema respiratório } \\
\text { humano no Ensino Fundamental. }\end{array}$ & $\begin{array}{l}\text { Mestrado Profissional Em Ensino de Ciências } \\
\text { e Matemática da Fundação Universidade de } \\
\text { Passo Fundo }\end{array}$ & $\begin{array}{l}\text { CAVALCANTI, } \\
2016\end{array}$ \\
\hline $\begin{array}{l}\text { Unidades de Ensino Potencialmente Signifi- } \\
\text { cativas para a Aprendizagem de Geometria } \\
\text { Analítica. }\end{array}$ & $\begin{array}{l}\text { Mestrado Profissional em Ensino de Ciências e } \\
\text { Matemática da Universidade de Caxias do Sul }\end{array}$ & FABRO, 2018 \\
\hline $\begin{array}{l}\text { Enfoque CTSA e as Unidades de Ensino Po- } \\
\text { tencialmente Significativas na formação de } \\
\text { professores de Ciências. }\end{array}$ & $\begin{array}{l}\text { Mestrado Profissional em Ensino de Ciências } \\
\text { Naturais e Matemática da Universidade Esta- } \\
\text { dual do Centro-Oeste }\end{array}$ & HAMMEL, 2018 \\
\hline
\end{tabular}

Fonte: Banco de Teses e Dissertações da CAPES (2018)

Para evitar uma aprendizagem de curto prazo com interpelações tradicionais, este trabalho consistiu no desenvolvimento de uma UEPS para o estudo da água e poluição na Perspectiva da Educação Ambiental Crítica, objetivando ir progressivamente diferenciando e integrando novos significados aos já existentes na estrutura cognitiva do estudante. Nesta direção, a UEPS foi desenvolvida em etapas, de forma a não separar o conhecimento acadêmico da realidade local, sendo então um instrumento de transformação social e política, tentando aproximar a alfabetização científica do acesso a ambientes já familiares ao estudante e incitando o seu agir. Atendeu-se aos princípios da Teoria da Aprendizagem Significativa Crítica (TASC), proposta por Moreira (2010), em que o educando, munido do conhecimento construído significativamente, poderá atuar como agente promotor de transformação ao propor possíveis soluções na sua comunidade. 


\section{Metodologia}

As etapas da UEPS foram desenvolvidas e aplicadas na Escola de Referência em Ensino Médio Professora Eurídice Cadaval, localizada no município de Itapissuma-PE. A abordagem se deu em uma turma de $2^{\circ}$ ano do Ensino Médio, composta por 30 estudantes que foram divididos em cinco equipes enumeradas de 1 a 5 . A UEPS foi construída em sete etapas, de acordo com os preceitos sugeridos por Moreira (2011). Cada etapa foi pensada para oferecer múltiplas abordagens com utilização de várias estratégias para cercar os estudantes e convidá-los, ativa e qualitativamente, a trabalharem a problemática da poluição do estuário local. No total, foram utilizadas 20 aulas com 50 minutos cada. O detalhamento da UEPS é apresentado no Quadro 2.

A Escolha do tema foi a etapa inicial onde foi realizada uma pergunta norteadora para que, individualmente e livremente, todos os estudantes respondessem ao seguinte questionamento: "quais as principais problemáticas ambientais, do município, que mais lhes inquietam?”. Esta etapa foi seguida pelo Levantamento do conhecimento prévio em que os estudantes foram divididos em cinco equipes e receberam informações sobre os pressupostos básicos para produção de um Mapa Conceitual. Em seguida produziram o primeiro mapa, tendo como pergunta: "qual é a importância da água para os seres vivos?”. No segundo momento, dessa mesma etapa, em oficina ministrada no auditório da escola, foi trabalhada a temática "Problemáticas Ambientais" que, ao utilizar a técnica de Brainstorming (tempestade de ideias), usou as respostas dos estudantes como ponto de partida para produzir, em tempo real, uma nuvem de palavras como feedback desse momento. 
Quadro 2: UEPS para o ensino da temática água e poluição na Educação Básica.

\begin{tabular}{|c|c|c|}
\hline Etapa & Aulas & Ações \\
\hline 1. Escolha do tema & 1 & Pergunta individual sobre a problemática que norteará a UEPS. \\
\hline $\begin{array}{l}\text { 2. Levantamento do } \\
\text { conhecimento prévio }\end{array}$ & 3 & $\begin{array}{l}\text { - Produção do } 1^{\circ} \text { mapa conceitual. } \\
\text { - Brainstorming (tempestade de ideias). } \\
\text { - Nuvem de Tags. Disponível em <https://voyant-tools.org> acesso em } \\
20 / 06 / 2019\end{array}$ \\
\hline $\begin{array}{l}\text { 3. Encontro de situação- } \\
\text {-problema introdutória }\end{array}$ & 8 & $\begin{array}{l}\text { - Aula deflagradora com textos sobre Resíduos sólidos; manguezais e es- } \\
\text { tuários; Enzima come PET; Conservação dos oceanos. Etapa executada } \\
\text { com a participação do professor do componente curricular de Química. } \\
\text { - Vídeos: Documentário Além do Lixo, Disponível em <https://www.youtu- } \\
\text { be.com/watch?v=alX5pP0eGAQ> acesso em } 19 / 11 / 2018 \text {, duração de } 15 \\
\text { minutos e } 25 \text { segundos; } \\
\text { - Sistema otimiza coleta de lixo na Holanda, disponível em <https://www. } \\
\text { youtube.com/watch?v=GYPphgOZ-kU> acesso em } 19 / 11 / 2018 \text {, duração } \\
\text { de } 2 \text { minutos e } 50 \text { segundos; } \\
\text { - Maré de lixo na República Dominicana, disponível em <https://www.you- } \\
\text { tube.com/watch?v=Fpbd4H I7qw> acesso em } 19 / 11 / 2018 \text {, duração de } \\
\text { - Aula de campo 1: visita ao Canal de Santa Cruz com professor pesqui- } \\
\text { sador, estudantes e participação de equipe de escoteiros do município. } \\
\text { Volta à escola com discussão sobre essa aula. } \\
\text { - Aula de campo } 2 \text { : visita ao Museu Espaço Ciência: Oficina Água, para } \\
\text { fazer análise físico-química da água coletada pelos alunos do Canal de } \\
\text { Santa Cruz. } \\
\text { - Palestra no auditório da escola: órgão convidado (CPRH). Tema: Co- } \\
\text { nhecer para Conservar. Participação externa: analista ambiental da APA, } \\
\text { Secretária do Meio Ambiente e agente popular de saúde. Participação } \\
\text { interna: estudantes do } 2^{\circ} \text { Ano e professor pesquisador. }\end{array}$ \\
\hline $\begin{array}{l}\text { 4. Diferenciação } \\
\text { progressiva }\end{array}$ & 2 & $\begin{array}{l}\text { - Utilização do game Kahoot. A partir dos textos científicos trabalhados na } \\
\text { etapa introdutória. Foram produzidas } 4 \text { perguntas e respostas, por equi- } \\
\text { pes, no total de } 20 \text {. O professor, com essas questões, formou um quiz } \\
\text { sobre resíduos sólidos e poluição dos estuários por águas residuais que } \\
\text { alimentou o game Kahoot. < } \underline{\text { https://create.kahoot.it/> }}\end{array}$ \\
\hline $\begin{array}{l}\text { 5. Situação-problema } \\
\text { complexa }\end{array}$ & 3 & $\begin{array}{l}\text { - Exposição com fotos relacionada ao ecossistema estuarino local com o } \\
\text { auxílio do professor do componente curricular de Arte. } \\
\text { - Produção de uma proposta de intervenção coletiva, auxiliados pelo pro- } \\
\text { fessor do componente curricular de Português, que a posteriori foi entre- } \\
\text { gue, pelos alunos, ao chefe do poder executivo municipal. }\end{array}$ \\
\hline $\begin{array}{l}\text { 6. Reconciliação } \\
\text { integrativa }\end{array}$ & 2 & $\begin{array}{l}\text { - Mesa Redonda. Tema: Quais as políticas públicas municipais relaciona- } \\
\text { das a resíduos sólidos e rede de tratamento de esgoto? } \\
\text { - Organização prévia: Professor pesquisador e gestor da escola. } \\
\text { - Mediadores da mesa: estudantes do } 2^{\circ} \text { ano. } \\
\text { - Convidados do poder público municipal: gestora da Secretaria de Meio } \\
\text { Ambiente e gestor da Secretaria de Limpeza Urbana. } \\
\text { - Convidados de organizações não governamentais: presidente da colônia } \\
\text { municipal de pescadores e presidente da Associação de Catadores de } \\
\text { Resíduos Sólidos. }\end{array}$ \\
\hline 7. Avaliação & 1 & $\begin{array}{l}\text { - Construção do } 2^{\circ} \text { mapa conceitual: Foi utilizado o aplicativo CmapTools. } \\
\text { < } \underline{\text { https://cmap.ihmc.us/cmaptools/> }}\end{array}$ \\
\hline
\end{tabular}

Fonte: SILVA (2019) 
A etapa da Situação-problema introdutória foi executada em quatro momentos. O primeiro momento contou com a participação do professor do componente curricular de Química, que em aula deflagradora, trabalhou textos científicos e vídeos relacionados à temática água e poluição marinha. Em um segundo momento foi realizada uma visita, guiada por um grupo de escoteiros, à margem do Canal de Santa Cruz. Na volta à escola, foi feita uma roda de discussão sobre a relação da visita com a temática. Em um terceiro momento aconteceu uma segunda aula de campo em espaço não formal, O Museu Interativo de Ciências de Pernambuco Espaço Ciência (Olinda - PE), com visita a duas oficinas, sendo uma direcionada à Área "Água”. Nessa oficina, foi realizada a análise físico-química de uma amostra de água coletada pelos estudantes do Canal de Santa Cruz (Itapissuma-PE). A segunda oficina foi uma exposição de doenças de veiculação hídrica, nesse caso, a do "Aedes aegypti: que mosquito é esse?". O quarto e último momento dessa etapa ocorreu, no auditório da escola, com uma palestra realizada por um analista ambiental da Agência Estadual de Meio Ambiente ( $\mathrm{CPRH})$ que é responsável pela Área de Proteção Ambiental de Santa Cruz (APA Santa Cruz), com o tema: "Aprender para Conservar". Além do Analista Ambiental, participaram dessa palestra como convidados do palestrante, a Secretária do Meio Ambiente do município de Itapissuma e um agente de saúde ambiental também do mesmo município, convidados que só enriqueceram o debate ocorrido pós-palestra.

Na etapa do desenvolvimento da Diferenciação progressiva foi solicitado aos estudantes uma releitura dos textos científicos trabalhados na etapa de situação problema introdutória. Em equipe, os estudantes foram orientados a elaborarem quatro perguntas e respostas, sendo duas sobre poluição por resíduos sólidos e duas sobre poluição por água de efluentes. No final da aula, 20 perguntas e respostas foram produzidas pelas equipes. Elas formaram um quiz, que alimentou o game Kahoot, que seria usado na próxima aula. Na sequência, em dupla e sem consultar material, os estudantes tiveram a oportunidade de jogar o game Kahoot.

A etapa da exposição de Situação-problema complexa teve a participação dos professores dos componentes curriculares de Artes e de Português. O componente de Artes trabalhou a temática "Pintura Acadêmica no Brasil - Fotografia: Arte na realidade". Foi então solicitado que cada uma das cinco equipes escolhessem uma fotografia da visita ao Canal de Santa Cruz e organizassem uma apresentação com slides com a foto escolhida e uma produção textual descrevendo a mesma. No com- 
ponente curricular de Português, a professora trabalhou o "Gênero Textual - Carta Argumentativa”. Então, foi solicitado que os estudantes, em equipe, produzissem um pequeno texto de reivindicações endereçado ao Chefe do Executivo Municipal. Eles deveriam elencar as problemáticas ambientais observadas ao longo do projeto, dando sugestões de soluções. Ao término, os estudantes produziram um texto coletivo que se transformou em uma carta propositiva que foi entregue ao Prefeito do Município de Itapissuma/PE.

Já a etapa para promoção da Reconciliação integrativa aconteceu no auditório da escola com a realização de uma atividade de mesa-redonda. As equipes elaboraram perguntas que seriam direcionadas aos convidados e elegeram alguns estudantes para mediarem as falas. O tema da mesa redonda foi “Quais as Políticas Públicas Municipais Voltadas ao Meio Ambiente?”. Os convidados foram os Secretários Municipais de Limpeza Urbana e de Meio Ambiente e, como representantes de instituições não governamentais, foram a Presidente da Associação de Pescadores e a Presidente da Associação de Catadores de Resíduos Sólidos. Da escola, participaram os trinta estudantes, professores e o gestor.

Por fim, a etapa de Avaliação visou analisar o impacto das etapas da UEPS na aprendizagem dos estudantes. Para isso, os estudantes produziram um segundo mapa conceitual após todas as intervenções. Foi então realizada uma comparação entre o mapa conceitual construído na etapa de conhecimentos prévios, com o segundo mapa, construído na etapa de avaliação, esse último, após os estudantes passarem pelas várias etapas da UEPS. A fim de obtermos indícios da promoção da aprendizagem significativa crítica (OLIVEIRA et al, 2017) foi avaliado como os conceitos apresentados no primeiro mapa foram articulados com novos conceitos no segundo mapa.

\section{Resultados e discussão}

A construção da UEPS foi iniciada com a indicação da temática “Água e Poluição" que foi escolhida pelos próprios estudantes ao serem indagados sobre a problemática ambiental local que mais os incomodavam. A escolha se justifica pelo fato da escola se encontrar numa cidade estuarina e eles, em sua maioria, serem filhos ou parentes de pescadores. O Estuário de Santa Cruz, localizado no município de Itapissuma/ $\mathrm{PE}$, tem grande relevância socioeconômica para a produção pesqueira, que abastece 
e gera renda para os munícipes no mercado local, além de munir grande parte da Região Metropolitana do Recife e do interior do Estado, sendo um dos estuários mais importantes do litoral do Estado de Pernambuco. Com base na referida temática, no Quadro 2 é apresentada a UEPS, objeto desse estudo.

Quanto à etapa 1 da UEPS, de posse das respostas ao questionamento feito aos estudantes sobre as problemáticas ambientais locais, constatou-se que majoritariamente foi citada a poluição do canal que banha a cidade como principal problemática a ser tratada. Esse resultado pode ser justificado tanto pelo fato da escola estar em uma cidade estuarina, como também devido a ter vários estudantes que são filhos ou parentes de pescadores. Cabe salientar que o tema pertence a um eixo transversal Meio Ambiente que pode ser trabalhado em qualquer unidade e por qualquer um dos componentes curriculares ofertados no Ensino Médio, conforme os PCNs (BRASIL, 1997).

Neste contexto, emerge um dos princípios para a aprendizagem significativa, a intencionalidade (AUSUBEL, 2003). Corroborando o que a TASC concebe, conforme estudo de Masini e Moreira (2008), o estudante pode, através de sua percepção, tematizar os assuntos a serem tratados e que, por sua compreensão, podem passar a ter significado. Essa foi a intencionalidade da pergunta feita a eles, a busca pelos significados. O que vai ao encontro do que diz Carvalho (2012), em relação à EAC, quando a autora aconselha evitar o caminho apressado e superficial na abordagem das questões ambientais, o que poderia reforçar uma consciência ambiental ingênua. Foi importante perceber o amadurecimento que, mesmo sem um vocabulário científico e/ou técnico, esses estudantes já conseguiam expressar sobre a temática nessa primeira etapa. Não só citaram, como justificaram suas respostas, evidenciando uma das premissas da AS que é a pré-disposição a aprender (Ausubel,1963).

Com relação à etapa 2 , a estratégia escolhida foi a produção de mapas conceituais em grupo para responder à pergunta foco "Qual é a relação da água com os seres vivos?". A principal função dos mapas de conceitos é evidenciar a associação de significados (MOREIRA, 2005). Dos cinco mapas conceituais produzidos, apenas dois mostravam um esboço de ligação do tema água com poluição. A Figura 1 mostra, como exemplo, um desses mapas conceituais. 
Figura 1: Mapa conceitual 1 produzido por estudantes de um dos grupos.

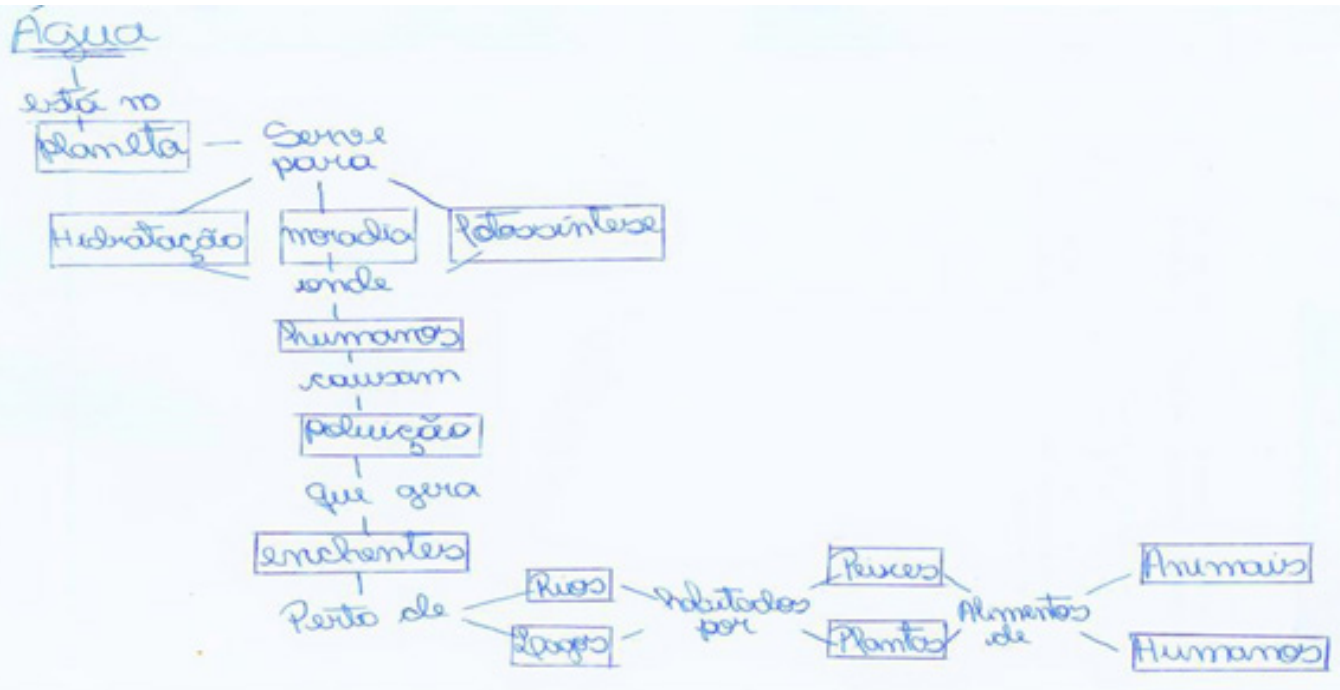

Pode-se inferir, a partir da análise do mapa, uma visão já diversificada do uso da água, visto que já levanta um viés crítico de sua relação com o meio ambiente, demostrando o conhecimento prévio que possuem sobre a temática. Contudo, foi observada uma linguagem desprovida de complexidade conceitual e acadêmica o que a classifica como ingênua. A principal estratégia advogada por Ausubel (2003), em situações como essa, é deliberadamente manipular a estrutura cognitiva com o uso dos organizadores prévios. Esses farão as pontes entre o que o estudante já tem e o que ele precisaria ter para aprender significativamente a temática estudada.

Mesmo tendo citado o conceito de poluição com alguns de seus subprodutos/ consequências geradas pelo homem, a análise evidencia a ausência de conceitos relacionados às questões hídricas locais, deixando claro as lacunas no domínio de conceitos relevantes sobre o tema (MASINI; MOREIRA, 2008). Algumas ideias ainda eram muito vagas, como por exemplo, as expostas na primeira e na segunda proposição do mapa: Planeta $\square$ Serve para $\square$ Hidratação; Moradia; Fotossíntese. Observa-se um certo grau de confusão principalmente quanto aos conceitos hidratação e fotossíntese, cujas relações com o conceito água permitem múltiplas interpretações.

Para complementar a etapa 2 , foi realizada uma dinâmica de grupo que utilizou a técnica de brainstorming, que estimulou o pensamento crítico e o posicionamento diante da temática. As interpelações ocorreram de forma rápida e calorosa, sendo 
robustamente respondidas pelos estudantes. O fechamento da dinâmica foi complementado com a chamada "nuvem de palavras", técnica que mostra a relevância de uma palavra pela quantidade de vezes que é repetida. Das 89 palavras produzidas, 5 tiveram maior relevância, devido à sua repetição: plástico, economia, impacto, ambientais e pesca. Esses resultados se mostraram coerentes com a problemática local por ficarem subentendidas questões atuais (plástico), socioeconômicas (economia e pesca) e ambientais (impacto e ambiente). Ao término dessas duas estratégias utilizadas nessa etapa, o professor pesquisador procurou seguir as recomendações de Ausubel (1963), ao sugerir que o ensino fosse baseado naquilo que o aprendiz já sabe.

$\mathrm{Na}$ etapa 3 foram levados em consideração alguns princípios facilitadores de uma Aprendizagem Significativa Crítica: princípio do conhecimento prévio, princípio da não centralidade do livro texto, princípio da não utilização do quadro de giz e da participação ativa do aluno e diversidade de estratégias de ensino (MOREIRA, 2006). Nesta direção, a temática foi apresentada sob diferentes perspectivas. De acordo com Gowin (1981), apresentar o tema de forma diversificada é importante para que o estudante perceba a relevância dos conceitos e manifeste uma intencionalidade para captá-los e internalizá-los. Assim, a primeira estratégia dessa etapa, contou com a participação do professor de Química que, em aula deflagradora, utilizou textos e vídeos.

Segundo os Parâmetros Curriculares Nacionais, PCNs, a leitura de um texto é apenas um recurso e não o essencial da aula, o que foi comprovado pelo entusiasmo da participação dos estudantes na aula (BRASIL, 1997). Assim, cabe ao professor problematizar para que se caminhe para a compreensão do conceito pretendido. Isso mostra uma característica fundamental do continuum que é a não dicotomização da relação existente entre práticas tradicionais e as práticas com potencialidades para serem significativas, o que segundo Ausubel (1963), só contribui para o fortalecimento da colaboração de ambas no processo de ensino-aprendizagem.

A segunda estratégia da etapa 3 foi uma visita ao Canal de Santa Cruz, baseando-se na premissa que o aprendizado que tem seu ponto de partida no universo vivencial comum ao estudante, desenvolve com vantagem o aprendizado significativo, aproximando o ensino e a escola do mundo real. Essa abordagem foi baseada em Ausubel, Novak e Hanesian (1980) ao relatarem que quando a natureza do assunto é apresentada de forma não arbitrária e não aleatória permite que ocorra uma relação não opressora e substantiva, quando ideias inerentes ao ser humano designam 
o significado lógico que irá determinar se uma atividade é ou não potencialmente significativa. Nessa aula de campo, um misto de leveza, encantamento, curiosidade e vários questionamentos dos estudantes fizeram com que o professor pesquisador percebesse que naquele momento eles sentiram estar adentrando de fato na problemática da poluição do Canal de Santa Cruz.

Esse exercício in loco ao estuário foi complementado com uma visita orientada pelos monitores ao museu interativo de Ciências - Espaço Ciência (Olinda/PE). As informações científicas instigaram a curiosidade como mais uma oportunidade de aprendizagem em direção à alfabetização científica, caracterizando o que Ausubel (1963) preconiza sobre ser no curso da aprendizagem significativa que o significado lógico dos materiais de aprendizagem se transforma em significado psicológico para o aprendiz. Ainda no Espaço Ciência os estudantes participaram de oficinas para análise físico-química da qualidade da água do estuário local onde receberam informações dos parâmetros oficiais de normalidade para um estuário. Por fim, em oficina sobre o Aedes aegypti assistiram a uma palestra que, de forma lúdica e com uso de recursos de tecnologias digitais, explorou vários aspectos dessa arbovirose, do seu transmissor e sua ligação com a água.

Como fechamento da etapa 3 , houve uma palestra na escola acerca do tema pelo órgão responsável pela área de proteção e conservação desse complexo estuarino - a Agência Estadual de Meio Ambiente de Pernambuco (CPRH) que criou a APA Santa Cruz - Área de Proteção Ambiental - para localmente exercer essa função. Verificou-se, com essas atividades, que a diversidade de situações-problema deu provável sentido aos novos conhecimentos (VERGNAUD, 1991). Os estudantes já começavam a mostrar motivação para-debater a temática de forma mais segura e desinibida. Assim, de acordo com Carvalho (2012), embora a formação de um sujeito ecológico tenha lugar em todas as experiências que nos formam durante a vida, a escola toma parte entre estas experiências como um elo muito importante deste ambiente-mundo em que vivemos.

Na etapa 4, correspondente à promoção do processo de diferenciação progressiva, o desafio é manter o interesse e o engajamento dos estudantes. A intenção dessa etapa foi observar se o estudante teria a habilidade de diferenciar progressivamente de forma inclusiva o que foi visto na etapa prévia e seguir abordando os aspectos mais específicos (MOREIRA, 2011). Nesta etapa foi escolhido um quiz produzido por eles, em equipe, com perguntas retiradas dos textos científicos usados na etapa 3. 
As perguntas produzidas nesse quiz serviram para fomentar um jogo, via Kahoot. O uso da plataforma Kahoot como um ambiente virtual de jogos proporcionou um contexto motivacional e desafiador no cotidiano da sala de aula. A média geral de acertos da turma foi de cerca de $85 \%$, resultado que evidencia um aproveitamento satisfatório das atividades realizadas até aquele momento, lembrando que a tecnologia sozinha não garante aprendizagem, assim como não irá transpor velhos paradigmas (DIESEL et al, 2017).

O professor pesquisador observou que, no que se refere às questões elaboradas sobre a problemática da poluição do Canal de Santa Cruz, os estudantes conseguiram ressignificar o ingênuo conhecimento prévio sobre a poluição hídrica estuarina com novos conceitos, com perguntas que partiram do geral para realidade local, como por exemplo: impacto ambiental $\mathrm{X}$ estuário (específico); poluição dos ecossistemas aquáticos $\mathrm{X}$ responsabilidade da coleta de resíduos sólidos no município (problema existente no município); aterro sanitário $\mathrm{X}$ consequências da poluição dos ecossistemas aquáticos (no estuário em questão, poluição por resíduos sólidos); manguezal como bioma que filtra impurezas X $60 \%$ do que se pesca nesse município vem do estuário local (classe trabalhadora do município prevalentemente de pescadores); destino final dos resíduos sólidos X importância das mudanças educativas (o que estava sendo trabalhado na UEPS), e outras. O game também serviu para testar controle, tempo de resolução de questões e equilíbrio emocional. Foram criados novos laços dentro da sala de aula, o que proporcionou que os mais tímidos e introvertidos externassem seu potencial, aproximando-se dos demais estudantes. Estes resultados estão de acordo com Moya Fuentes et al. (2016) que compara a sala de aula, temporariamente, a um espetáculo através do jogo.

Já na etapa 5, na perspectiva de apresentar situações mais complexas sobre a temática em estudo, foram envolvidos os componentes curriculares de Português e Artes. Procurou-se ir ao encontro do que diz Moreira (2010), sobre estruturar o conhecimento através da presença de novas situações-problema que possam retomar as características mais relevantes das temáticas trabalhadas nas etapas anteriores. Segundo Ausubel (1980), esse é o momento em que o que é mais significativo e adequado interage com a nova informação. Nessa direção, no componente curricular de Artes, por exemplo, os estudantes apresentaram uma exposição dos registros fotográficos produzidos na aula de campo ao Canal de Santa Cruz (Etapa 3). A intenção era observar se eles demonstrariam progressivo entendimento da com- 
plexidade da problemática hídrica ao explicar o material produzido e escolhido por eles para exposição. Ao justificarem a fotografia escolhida, foram intencionalmente convidados a se darem conta da magnitude de informações que pode ser revelada do meio ambiente em uma fotografia (LOUREIRO, 2014).

De acordo com Leff (2010), a crise ambiental é um problema epistemológico que possibilita a discussão e a reflexão do conhecimento e dos saberes ambientais. A Fotografia e o texto escrito pelas equipes evidenciavam que, ao contemplar a paisagem e enquadrá-la em um plano fotográfico, os problemas ambientais já não passavam despercebidos por eles. Percebe-se então, a clareza e o amadurecimento na voz de um dos estudantes quando afirma: "Mesmo que a poluição seja microscópica como a água que sai da canaleta e deságua no canal, ela é tão prejudicial quanto a macroscópica, causando como "subproblema", prejuízo ao estuário e a quem dele se serve como fonte de renda". Os estudantes e suas equipes conseguiram fazer um resgate crítico através da paisagem de um projeto municipal de saneamento que não levou em conta a futura agressão ao meio ambiente. Conseguiram, na sua explanação, associar às várias consequências oriundas dessa ação mal planejada, no que se refere as questões ambientais, econômicas e sociais. As imagens oferecem registros restritos muito poderosos das ações temporais e dos acontecimentos reais (BAUER e GASKEL, 2017).

Por outro lado, no componente curricular de Português, o tema de poluição foi abordado, a partir do estudo do gênero textual Carta Argumentativa. Cartas foram escritas e coletivamente transformadas em uma Proposta de Intervenção pelos grupos de estudantes com sugestões de melhorias para a divulgação de medidas de combate à poluição do estuário. A proposta final foi direcionada ao chefe do executivo do município. Foi uma oportunidade para os estudantes "negociarem significados" e "abandonarem as narrativas", de acordo com o que preconizam alguns princípios da TASC (MOREIRA, 2010). Essa é a mesma linha de entendimento dos PCNs (BRASIL, 1997), ao preconizar que seja dada ao estudante a oportunidade de construir modelos explicativos e linhas de argumentação. Os estudantes foram instigados a participarem e questionarem, além de valorizarem as atividades coletivas que propiciaram discussões, resultando na elaboração conjunta de ideias práticas que poderão sair dos muros da escola e se ambientar com a sociedade.

O mais importante neste cenário é proporcionar não só a autonomia do estudante, mas o seu posicionamento diante de um problema com mudanças de atitudes. Para 
alegria de todos, a carta foi respondida pelo gestor público, mostrando que ações escolares podem ir além das discussões pedagógicas. A carta-resposta do governo municipal mostrou que existe um vasto campo de possibilidades de parcerias que podem acontecer entre o seguimento escolar e órgãos governamentais. "Essa constatação revela a necessidade de fortalecer os vínculos da escola com atores envolvidos na gestão da Educação Ambiental e fora dela - entre os quais a comunidade, universidades e poder público" (LOUREIRO, 2007, p. 58).

Para a etapa 6 , destinada à promoção do processo de reconciliação integrativa, foi organizada uma mesa-redonda com os principais atores relacionados à temática. Participaram representantes do Governo Municipal (Secretária do Meio Ambiente e Secretário de Limpeza Urbana), organizações não-governamentais (presidentes da colônia de pescadores e da Associação de Catadores de Resíduos Sólidos) e os estudantes como sociedade civil. As perguntas e a quem seriam endereçadas foram elaboradas autônoma e previamente pelos estudantes, que inclusive presidiram o evento tendo, ao mesmo tempo, algo prático e real ligado ao tema. Isto serviu de parâmetro observacional de como estavam o nível de entendimento dos novos conhecimentos dos estudantes nessa etapa da UEPS, pois, ao formular as perguntas, os discentes iriam argumentar com base nos conceitos, concepções e informações assimilados, reconciliando ideias e promovendo a TASC (MOREIRA, 2017).

O ensino da Biologia, na perspectiva da Educação Ambiental Crítica, tornou possível aos estudantes a compreensão de que há uma ampla rede de relações entre o que é visto na escola, como produção científica, e o contexto social com os contextos econômico e político. Essa etapa da UEPS foi mais uma oportunidade para os estudantes irem e voltarem com o conteúdo temático e demonstrarem se tinham ancorado ou não novos conhecimentos aos já existentes (MOREIRA, 2011).

Várias perguntas foram elaboradas em uma prévia discussão entre as equipes e evidenciaram o grau de maturidade dos estudantes sobre a temática, o que se refletiu na postura crítica e autônoma que assumiram ao serem os protagonistas ativos do evento. Esse resultado confirma o que Ausubel, Novak e Hanesian (1980) discutem sobre a relevância de se identificar e organizar conceitos e proposições. Todavia, essa relação entre as ideias não precisa ser rigorosamente escrita e unidirecional. Para um evento em que os estudantes precisariam fazer uso da criticidade necessária ao momento e ao tema, eles se mostraram cognitivamente preparados para essa fase da UEPS sem necessariamente estarem fazendo uma atividade 
escrita tradicional. Isso ficou claro ao observar o nível da abordagem feita por eles conforme evidenciado nos exemplos abaixo:

- "Por que apenas uma parte da margem do Canal (próxima à praça central) é limpa?"

- "O que a Secretaria de Limpeza Urbana tem feito para resolver o problema dos resíduos sólidos depositados em locais indevidos na cidade?”

- "Educação Ambiental é um tema bastante falado. A colônia de pescadores, a Associação de Catadores de Resíduos e a Secretarias aqui presentes têm projetos sendo realizados sobre essa temática? Se tem, quais são?”

- “O que vocês estão fazendo para conscientizar as pessoas a não poluírem o canal?"

Moreira (2012) sugere que avaliação de uma UEPS deve ser em termos de busca de evidências, progressividade e não linearidade da aprendizagem. Nesse estudo, a avaliação foi essencialmente formativa, considerando não comportamentos finais, mas transformações, concepções e reflexões ao longo do processo e fazendo uso da recursividade quando necessária, visto que as novas proposições evidenciaram uma diferenciação progressiva dos conceitos que foram se contextualizando e se reconciliando integralmente a um amadurecimento cognitivo exposto pela ferramenta escolhida para avaliação (MOREIRA, 2011).

Nesta direção, para avaliação/validação da UEPS foi construído um segundo mapa conceitual pelos mesmos estudantes das equipes que fizeram os primeiros mapas. Segundo Novak e Cañas (2010) essa produção é uma forma de estimular o desempenho cognitivo e, por esse motivo, sua utilização pode ser uma poderosa ferramenta tanto de aprendizagem como de avaliação. Conforme Aquino e Chiaro (2013), o mapa conceitual então se constitui em uma ferramenta de aprendizagem para o estudante, à medida que auxilia no planejamento dos estudos, preparação para avaliações e resolução de problemas. Assim, nessa última etapa da UEPS foram produzidos um total de cinco mapas, sendo um deles mostrado na Figura 2. Este mapa foi construído pelo mesmo grupo que construiu o mapa da Figura 1 , para fins de comparação.

Na comparação entre os mapas das Figuras 1 e 2, observou-se que, conforme indica Moreira (2012), ao se ancorar representações válidas da estrutura conceitual/ proposicional de um novo conhecimento ao já existente, torna-se tal estrutura mais 
expandida, e essa nova configuração ficou evidenciada na Figura 2. Assim, a análise do mapa conceitual da Figura 2, mostra uma evolução na direção de uma preocupação ambiental crítica fortemente relacionada com as questões sociais, econômicas e políticas do município, visto que na sociedade contemporânea, não basta adquirir novos conhecimentos de maneira significativa, é preciso adquiri-los criticamente. Ao mesmo tempo que é preciso viver em sociedade e integrar-se a ela, é também necessário ser crítico em relação a ela (Moreira, 2006).

Figura 2: Mapa Conceitual 2 produzido por estudantes do mesmo grupo responsável pelo mapa conceitual 1, utilizando o CmapTools.

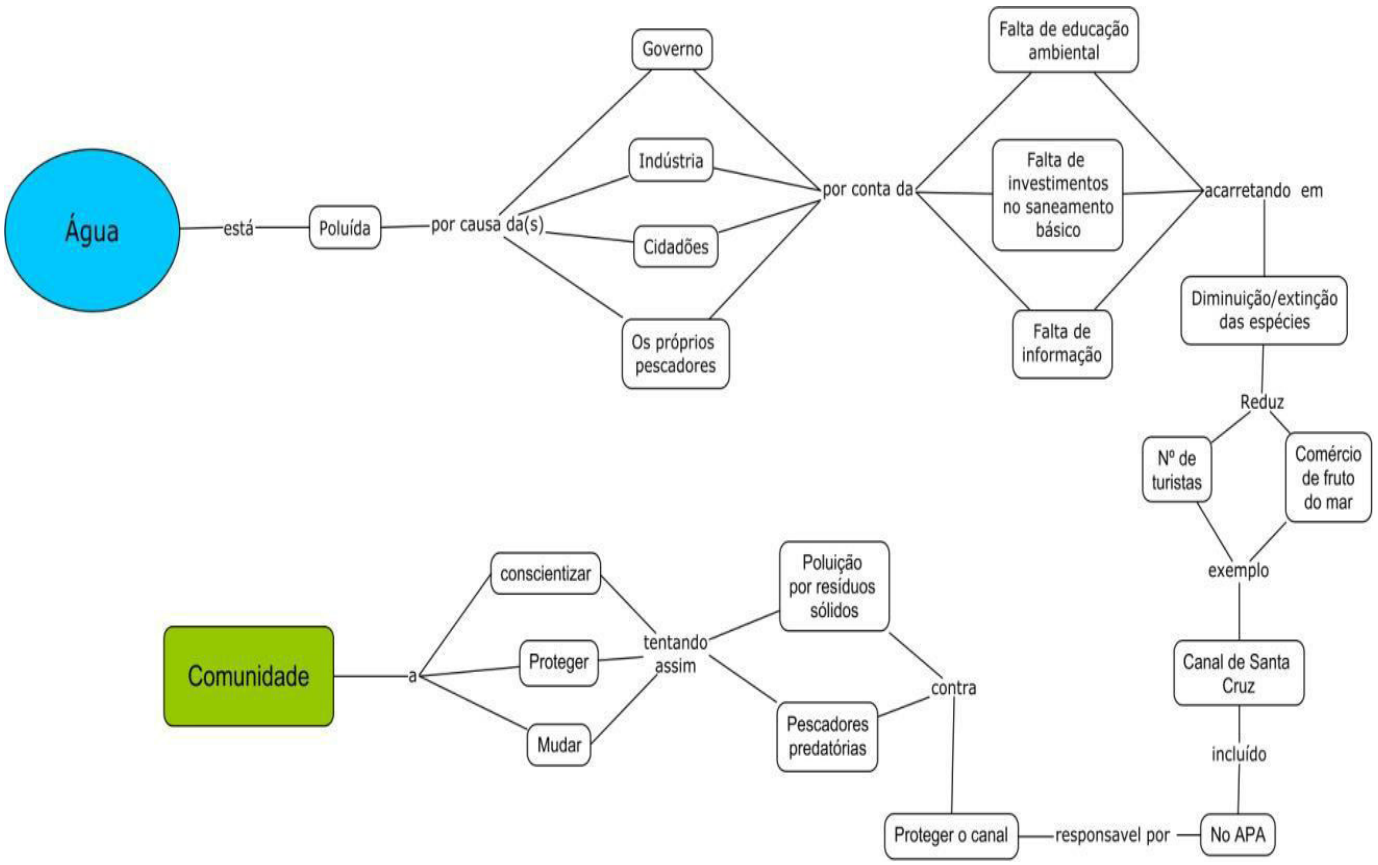

A equipe, partindo inicialmente do conceito de água e poluição, como os conceitos mais inclusivos, deu rápido seguimento ao processo de diferenciação progressiva retomando as características mais relevantes do conteúdo em questão. Porém, passou a apresentar uma forte perspectiva integradora que também evidencia a transformação ocorrida na aprendizagem relacionada aos conceitos socioambientais ligados ao estuário. Percebem-se modificações cognitivas capazes de referenciar progressivamente os conceitos causadores da poluição. Na proposição Poluída $\rightarrow$ Por causa $\rightarrow$ Governo; Indústria; Cidadãos; Pescadores, por exemplo, os estudantes 
mostram que conseguem diferenciar as causas da poluição com a reconciliação de saberes ao articular esta proposição na sequência Governo; Indústria; Cidadãos; Pescadores $\rightarrow$ Por conta da $\rightarrow$ falta de educação ambiental; investimento em saneamento básico; falta de informação. Tal articulação nos permite inferir que os estudantes passaram a identificar as consequências provenientes das principais causas, em um movimento crítico e reflexivo que foi, certamente, gerado ao longo das etapas da UEPS.

Por fim, também é possível observar na Figura 2 que os estudantes partem de conceitos mais gerais para conceitos mais específicos mostrando o evidente processo de diferenciação progressiva. Um exemplo está na proposição Número de Turistas; Comércio de Frutos do Mar $\rightarrow$ Exemplo $\rightarrow$ Canal de Santa Cruz. Nesta proposição os estudantes externalizam novos significados em oposição aos ingênuos conceitos vistos no primeiro mapa conceitual (Figura 1). Estas são evidências da ancoragem de novos conceitos aos conceitos prévios numa demonstração da transformação do conhecimento existente, ou seja, uma aprendizagem significativa em curso (MOREIRA, 2017). Acreditamos que este foi o primeiro passo para que os estudantes sejam futuros transformadores do meio em que vivem, com a escola passando a ter um papel que vai muito além das paredes da sala de aula.

\section{Considerações finais}

A UEPS desenvolvida neste trabalho utilizou-se de vários recursos e ferramentas que puderam proporcionar a união de uma temática de magnitude transversal, como é o caso do Meio Ambiente, na perspectiva da junção de uma Educação Ambiental Crítica para promoção de uma Aprendizagem Significativa Crítica. Juntas, elas foram gradativamente impulsionando os estudantes, ao longo do processo, a se tornarem mais participativos, ativos, inovadores e, acima de tudo, questionadores.

O relato acima evidencia as possibilidades de outros profissionais da educação utilizarem essa UEPS em suas realidades. Por sua versatilidade, molda-se a qualquer tema ou componente curricular que se propuser a abordar. Nesta direção, a UEPS não é pensada e executada "para" o estudante, devendo sempre ser pensada e executada "com" o estudante que é o caminho do êxito de uma UEPS. Ao respeitar a história do estudante e romper com as velhas práticas de ensino, o legado é de uma aprendizagem que seja potencialmente significativa e preferencialmente crítica. 
A UEPS, concomitantemente ao estudo, rendeu alguns desdobramentos que corroboraram para sinalizar a acertada direção de sua aplicação, especialmente no que se refere à sua demanda social, pois os estudantes foram convidados, a participarem de um projeto piloto da Secretaria Municipal de Limpeza Urbana (Itapissuma/PE) na comunidade, sobre o descarte de resíduos sólidos em lugares indevidos em diversas áreas do município.

Além disso, uma UEPS propicia ao professor o real papel mediador em detrimento de posturas tradicionais que visam a apresentação de regras e de informações descontextualizadas, que apenas desmobilizam e servem para perpetuar a construção de uma visão de que a aprendizagem está restrita a terminar nas paredes de uma sala de aula. Por fim, a UEPS também evidencia a satisfação de entender que o estudante tem o direito de participar ativamente de seu processo de ensino-aprendizagem e a riqueza da percepção da realidade que ele pode trazer para esse processo, bastando apenas que se crie ambientes propícios, materializando os ganhos reais para uma educação pautada na promoção de uma aprendizagem significativa.

\section{Potentially significant teaching unit for the study of water and pollution from the perspective of critical environmental education}

\section{Abstract}

Coastal pollution is among the most serious environmental problems nowadays. Schools have a fundamental role on promoting and improving environmental awareness for current and future generations. With this aim, it is important they take actions that integrate different knowledge fields with the use of teaching tools and strategies, which are potentially significant. With this purpose, a Potentially Meaningful Teaching Unit (PMTU) was developed on the theme "Water Pollution in Basic Education" and applied to high school students from a public school from Pernambuco state. The PMTU was conceived using a sequence of teaching actions in an interdisciplinary way by using different strategies and learning tools. Learning evaluation was carried out by using concept maps produced by the students before and after applying the PMTU. These maps showed that the new concepts were anchored to the student's previous knowledge, an indication of meaningful learning was achieved. PMTU sequence helped the students to play major roles in learning to better understand the complexity of the coastal pollution problem. In addition, it also aided them in developing environmental, social, and political responsibility.

Keywords: Meaningful Learning. Science Teaching. Conceptual Map. PMTU. 


\section{Referências}

AQUINO, Kátia Aparecida da Silva; CHIARO, Sylvia de. Uso de Mapas Conceituais: percepções sobre a construção de conhecimentos de estudantes do ensino médio a respeito do tema radioatividade. Revista Ciências \& Cognição, Passo Fundo, v. 18, n. 2, p. 158-171, 2013.

AUSUBEL, David Paul. The Psychology of Meaningful Verbal Learning. New York. Grune \& Stratton: 1963.

AUSUBEL, David Paul. Aquisição e Retenção de Conhecimentos: uma Perspectiva Cognitiva. Lisboa: Plátano, 2003.

AUSUBEL, David Paul; NOVAK, Joseph Donald; HANESIAN, Helen. Psicologia Educacional. Rio de Janeiro: Interamericana, 1980.

BAUER, Martin; GASKEL, George. Pesquisa qualitativa com texto, imagem e som: um manual prático. Petrópolis: Vozes, 2017.

BRASIL. Ministério da Educação. Base Nacional Comum Curricular (BNCC). Secretaria de Educação Básica. Brasília/DF: 2018. Disponível em: http://basenacionalcomum.mec.gov.br/images/ BNCC_EI_EF_110518_versaofinal_site.pdf. Acesso em: 25 jul. 2019.

BRASIL. Ministério da Educação. Parâmetros Curriculares Nacionais (PCN). Secretaria de Educação Básica. Brasília/DF: 2012. Disponível em: http://portal.mec.gov.br/index.php?option=com_ content\&view=article\&id=12640\%3Aparametros-curriculares-nacionais $10=-a 4-0$-series\&catid195\%3Aseb-educacao-basica\&Itemid=859. Acesso em: 12 jul. 2019.

BRASIL. Ministério do Meio Ambiente. Ética e Sustentabilidade. Caderno de debate Agenda 21 e sustentabilidade. Brasília/DF: 2006. Disponível em: http://www.mma.gov.br/agua.html. Acesso em: 22 mar. 2019.

CAPES. Coordenação de Aperfeiçoamento de Pessoal de Nível Superior. Catálogo de Teses e Dissertações. Disponível em: https://catalogodeteses.capes.gov.br/catalogo-teses/\#!/. Acesso em: 20 de mar. 2019

CARVALHO, Isabel Cristina de Moura. O sujeito ecológico: a formação de novas identidades na escola. In: PERNAMBUCO, Marta; Paiva, Irene. (Org.). Práticas coletivas na escola. 1. ed. Campinas: Mercado de Letras, 2012.

CARVALHO, Isabel Cristina de Moura; TONIOL, Rodrigo. Ambientalização, cultura e educação: diálogos, traduções e inteligibilidades possíveis desde um estudo antropológico da educação ambiental. Revista Eletrônica do Mestrado em Educação Ambiental, Rio Grande/RS, v. 1, p. 28-39, 2010.

CAVALCANTI, Juliano. Unidade de Ensino Potencialmente Significativa para estudo do sistema respiratório humano no Ensino Fundamental II. Passo Fundo: UPF, 2016. Mestrado Profissional em Ensino de Ciências e Matemática Instituição de Ensino, Universidade de Passo Fundo, 2016.

COIMBRA. José de Ávila Aguiar. Considerações sobre a interdisciplinaridade. In: Arlindo Philippi; TUCCI, Carlos Morelli; HOGAN, Daniel Joseph; NAVEGANTES, Raul. Interdisciplinaridade em Ciências Ambientais. São Paulo: Signus Editora, 2000. 
CONTIN, Rita de Cassia. Ensino de conceitos de termodinâmica: estação meteorológica como possibilidade de aprendizagem em física. Cuiabá: UFMT, 2017. Mestrado Profissional em Ensino de Ciências Naturais Instituição de Ensino, Universidade Federal de Mato Grosso, 2017.

DIESEL, Aline; BALDEZ, Alda Leila Santos; MARTINS, Silvana Neumann. Os princípios das metodologias ativas de ensino: uma abordagem teórica. Revista Thema. Pelotas/RS, v. 14, n. 1, 268-288, 2017.

FABRO, Rafaela Regina. Unidades de Ensino Potencialmente Significativas para a Aprendizagem de Geometria Analítica. Caxias do Sul: UCS, 2018. Mestrado Profissional em Ensino de Ciências e Matemática Instituição de Ensino, Universidade de Caxias do Sul, 2018.

FILHO, Alderico dos Santos Sousa. Inserção dos conceitos da radiação do corpo negro no ensino médio através de uma sequência didática baseada em uma UEPS. Manaus: IFAM, 2018. Mestrado Profissional em Ensino de Física, Instituto Federal de Educação, Ciência e Tecnologia do Amazonas, 2018.

GOWIN, Dixie Bob. Educating. Ithaca, New York: Cornell University Press, 1981.

HAMMEL, Cristiane. Enfoque CTSA e as Unidades de Ensino Potencialmente Significativas na formação de professores de Ciência. Guarapuava: Unicentro, 2018. Mestrado Profissional em Ensino de Ciências Naturais e Matemática Instituição de Ensino, Universidade Estadual do Centro-Oeste, 2018.

LEFF, Enrique. Epistemologia Ambiental. 5. ed. São Paulo: Cortez, 2010.

LIMA, Adriana Fatima de. Proposta de uma UEPS para ensinar o efeito fotoelétrico no ensino médio. Brasília: UnB, 2018. Mestrado Profissional em Ensino de Física, Universidade de Brasília, 2018.

LOUREIRO, Carlos Frederico Bernardo. Trajetória e fundamentos da Educação Ambiental. 4. ed. São Paulo: Cortez, 2014.

LOUREIRO, Carlos Frederico Bernardo. Conteúdos, gestão e percepção da educação ambiental nas escolas. In: TRAJBER, Rachel; MENDONÇA, Patrícia Ramos. (org.). Educação na diversidade: o que fazem as escolas que dizem que fazem educação ambiental. Brasília: Secretaria de Educação Continuada, Alfabetização e Diversidade, 2007.

LOUREIRO, Carlos Frederico Bernardo. Problematizando conceitos: contribuição à práxis em Educação Ambiental. In: LOUREIRO, Carlos Frederico B.; LAYRARQUES, Philippe Pomier; CASTRO, Ronaldo Souza de (Orgs.). Pensamento Complexo, Dialética e Educação Ambiental. São Paulo: Cortez, 2006.

MACHADO, Carlos Roberto da Silva; MORAES, Bruno. Os conflitos como momento de ruptura da hegemonia: contribuições à sociologia e à educação ambiental a partir de Henry Lefebvre. Revista Novos Rumos Sociológicos (NORUS), Pelotas, v. 4, n. 6, p. 115-136, jul./dez. 2016.

MASINI, Elcie Salzano.; MOREIRA, Marco Antonio. Aprendizagem Significativa: condições para ocorrência e lacunas que levam a comprometimentos. São Paulo: Vetor, 2008.

MEDEIROS, Jaqueline Suenia Silva de. Proposta de UEPS abordando conceitos envolvidos no processo de ensino e aprendizagem da eletroquímica. Natal: UFRN, 2018. Mestrado Profissional em Ensino de Ciências Naturais e Matemática, Universidade Federal do Rio Grande do Norte, 2018. 
MENDONCA, Marcos de Oliveira. Proposta de construção de uma sequência didática abordando tópicos de Cosmologia no Ensino Médio. Brasília: UnB, 2018. Mestrado Profissional em Ensino de Física, Universidade de Brasília, 2018.

MOREIRA, Marco Antonio. Mapas conceituais e aprendizagem significativa. Revista Chilena de Educação Científica, v. 4, n. 2, p. 38-44, 2005.

MOREIRA, Marco Antonio. A teoria da aprendizagem significativa e sua implementação em sala de aula. Brasília: Editora Universidade de Brasília, 2006.

MOREIRA, Marco Antonio. Aprendizaje Significativo Critico. Indivisa: Boletín de Estúdios e Investigación. 2. ed., n. 6, p. 83-101, 2010.

MOREIRA, Marco Antonio. Teorias de aprendizagem. 2. ed. São Paulo: Epu, 2011.

MOREIRA, Marco Antonio. O que é afinal aprendizagem significativa? Revista cultural La Laguna Espanha, 2012. Disponível em <http://moreira.if.ufrgs.br/oqueeafinal.pdf> Acesso em 18 jan. 2019.

MOREIRA, Marco Antonio. Ensino e aprendizagem significativa. São Paulo: Editora Livraria da Física, 2017.

MOREIRA, Marcos Antonio; MASINI, Elcie Salzano. Aprendizagem Significativa: a teoria de David Ausubel. 2. ed. São Paulo: Centauro, 2006.

MOYA FUENTES, María del Mar; CARRASCO ANDRINO, María del Mar; JIMÉNEZ PASCUAL, Almudena.; RAMÓN MARTÍN, Aitana; SOLER GARCÍA, Carolina.; VAELLO, Teresa. El aprendizaje basado en juegos: experiencias docentes en la aplicación de la plataforma virtual "Kahoot”. Actas XIV Jornadas de Redes de Investigación en Docencia Universitaria. Alicante, 2016.

NOVAK, Joseph Donald; CAÑAS, Alberto. A teoria subjacente aos mapas conceituais e como elaborá-los e usá-los. Revista Práxis Educativa, Ponta Grossa, v. 5, n. 1, p. 9-29, jan./jun. 2010. Disponível em: http://cmap.ihmc.us/docs/pdf/teoriasubjacenteaosmapasconceituais.pdf. Acesso em: 12 dez. 2018.

NUNCIO, Ariane Pegoraro. Contribuições de unidades de ensino potencialmente significativas (UEPS) para a disciplina de ciências do ensino fundamental. Caxias do Sul: UCS, 2016. Mestrado Profissional em Ensino de Ciências e Matemática Instituição de Ensino, Universidade de Caxias do Sul, 2016.

OLIVEIRA, José Antônio Bezerra de; SILVA, Cristiane Jussara da; FERREIRA, Bruno Luiz Barbosa; AQUINO, Kátia Aparecida da Silva. Mapas conceituais na avaliação de sequências didáticas potencialmente significativas para o ensino de Biologia na Educação Básica. Cadernos de Estudos e Pesquisa na Educação Básica, Recife, v. 3, n. 1, p. 35-51, 2017. Disponível em: https://periodicos.ufpe.br/revistas/cadernoscap/article/view/230849. Acesso em: 22 mar. 2019.

SILVA, Cristiane Jussara da. Unidade de ensino potencialmente significativa para o estudo da água e poluição na educação básica. Recife: UFPE, 2019. Dissertação de Mestrado, Programa de Pós-Graduação em Ensino de Ciências Ambientais, Universidade Federal de Pernambuco, 2019.

VERGNAUD, Gérard. La théorie dês champs conceptuels: Reacherches em Didactique dês Mathématiques, Grenoble. v. 10, n. 23, p. 133-170, 1990. 